\title{
Photodynamic Therapy in Conjunction with 5-Aminolevulinic Acid 5\% Impact of Efficacy in Management of Acne Vulgaris
}

\author{
Al-Sadat Mosbeh*, Ahmed Aladl and Ahmed Shawky \\ Department of Dermatology, Faculty of Medicine, Al-Azhar University, Egypt
}

Submission: June 22, 2020; Published: July 01, 2020

*Corresponding author: Al-Sadat Mosbeh, Department of Dermatology, Faculty of Medicine, Al-Azhar University, Cairo, Egypt

Abstract

Background: Pathological basis for acne vulgaris is multifactorial in origin that involves integration of various factors involving inflammation in conjunction with raised sebum productivity levels causing pilosebaceous unit obstruction becoming a suitable media for propionebacterium acnes, Particular wave lengths used in photodynamic therapy in conjunction to photosensitizers applied to affected skin have revolutionized the management course of acne vulgaris disease particularly severe forms

Aim: Assessing the effectiveness and toleration at clinical levels of $5 \%$ aminolevulinic acid gel as a thermosetting agent in conjunction with photo dynamic therapy red-light in the management of mild to moderate forms of acne vulgaris disease.

Methodology: The research study is a prospective fashioned study conducted in Al-Azhar university Hospitals between October 2018 and January 2019

Results: GAG score before, at end of treatment, at last follow up was statistically significant $p$ values $=0.001$, whereas percentage of improvement at end of treatment and at last follow up were not statistically significant $p$ value $=0.378,0.617$, consecutively.

Conclusion: Photodynamic therapy mode in conjunction of the photosensitizing agent aminolaevulinic acid 5\% is a promising management mode for moderate to severe forms of acne vulgaris however future research studies are required to be multicentric in fashion with larger sample sizes to verify the research study results with consideration of racial and ethnic differences as a factor that could affect the responsiveness rate of treatment.

Keywords: Photodynamic Therapy; 5-Aminolevulinic Acid 5\%; Acne Vulgaris

\section{Introduction}

Acne vulgaris is a chronic form of inflammatory skin diseases that characterized by presence of open and closed comedones affecting the face truncal and chest regions that clinically presenting as papules ,nodules affecting the cosmetic appearance of the face casing psychosocial issues particularly in teenager age groups [1,2]. Retinoids and antibiotics are considered the cornerstone management pathways however antibiotic resistance issues and compliance to treatment could cause in complete resolution with permanent scarring that could affect the cosmetic appearance particularly in moderate and severe forms of acne. Innovative treatments using photo dynamic therapy to eliminate the main causative infectious agent propionebacterium that could activate the toll receptors triggering the pathophysiological process of disease development [3,4]. Various dermatological research studies have demonstrated that P. acnes could trigger inflammatory skin issues by stimulating Toll-like receptor type 2 and type 4 that subsequently activate inflammatory cytokines productivity levels to increase e.g. interleukin (IL)-1, IL-8, and IL-12 [5,6]. Pathological basis for acne vulgaris is multifactorial in origin that involves integration of various factors involving inflammation in conjunction with raised sebum productivity levels causing pilosebaceous unit obstruction becoming a suitable media for propionebacterium acnes, particular wave lengths used in 
photodynamic therapy in conjunction to photosensitizers applied to affected skin have revolutionized the management course of acne vulgaris disease particularly severe forms ,however issues have arisen as regards the side effects and the capacity and safety levels to complete the course and dosage of treatment protocol required $[7,8]$.

At cellular and molecular levels, the photodynamic therapy in conjunction with photosensitizers create oxygen free radicals that eliminate the infectious agent causing the disease cascade of pathological events $[9,10]$. Blue-light $(405 \mathrm{~nm})$ and Red-light (630 $\mathrm{nm}$ ) lamp forms are frequently implemented in photodynamic therapy that is considered one of the effective management protocols for acne. 5-aminolevulinic acid an agent when exposed to particular wave lengths causes triggering of the photosensitizer and subsequent reactive oxygen Species productivity that have a cytotoxic impact. an interesting action of photodynamic therapy that was revealed and displayed by various research groups of investigators in which it was observed that direct form of photodynamic therapy could cause injurious insult of sebaceous glands leading to inhibition of sebum productivity .furthermore another remarkable action that was demonstrated by various researchers in which P. acnes are killed by photodynamic therapy could cause follicular sterilization, besides immunomodulatory manipulation suggested by various research studies and inflammatory impact demonstrated at cellular and molecular levels by reducing expressive activities of TLR2 and TLR4 [1113]. Interestingly follicular obstructive issues from therapy could be decreased considerably by changing keratinocyte shedding management $[14,15]$.

\section{Aim of the work}

Assessing the effectiveness and toleration at clinical levels of $5 \%$ aminolaevulinic acid gel as a thermosetting agent in conjunction with photo dynamic therapy red-light in the management of mild to moderate forms of acne vulgaris disease.

\section{Methodology}

The research study is a prospective fashioned study conducted in Al-Azhar university Hospitals between October 2018 and January 2019. Main inclusive research criteria Have been as follows cases having non-inflammatory or inflammatory acne vulgaris (papulo-pustolar) affecting face and trunk; age above 18 years old, non-pregnant; contraindicated or unresponsive to classic treatment of acne e.g. oral and topical antibiotics and/ or retinoids. Exclusive research criteria have been the following existence of other acute dermatological illnesses other than acne vulgaris, topical acne therapy within the prior 2 weeks or systemic retinoids within the past 6 months, keloids history, or disorders of photosensitivity, pregnancy and lactation.

\section{PDT procedures}

A Clinical research prospective trail conducted ion 40 research study subjects having moderate to severe forms of acne vulgaris A $5 \%$ aminolaevulinic acid thermosetting gel chosen for performing the research study. Research study subjects have undergone treatment every other week for a total of three sessions for each case. During the aminolaevulinic acid incubation period of 120 minutes, cases have been kept away from sunlight, to prevent of the photosensitizer triggering. Cases have been irradiated by usage of a $630 \mathrm{~nm}$ red-light source at $25 \mathrm{~mJ}$ for a mean of 15 minutes. The distance from the lamp to the affected area of the skin have been $15 \mathrm{~cm}$, cold water was applied to reduce redness and pain immediately after irradiation. Three Photodynamic therapy management sessions, each one conducted every 2 weeks, cases have been evaluated clinically and by using GAG scoring system with evaluation of skin tolerability and the existence of side effects after every performed photodynamic therapy session (Figure 1). Clinical follow-up visits, to assess the patients, have been conducted 2 and 4 weeks after the last session of photo dynamic therapy.

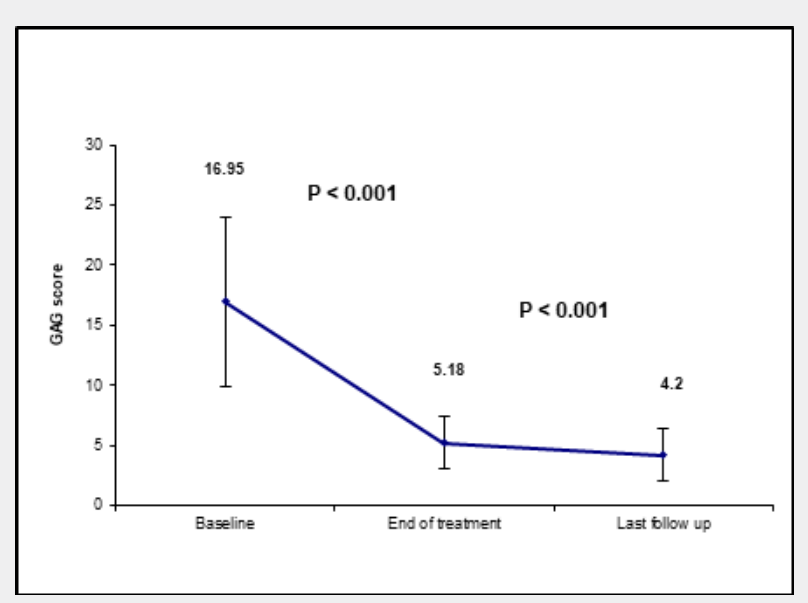

Figure 1: Reveal and display that the GAG score Mean \pm SD at baseline, end of treatment, last follow up $=16.95 \pm 7.05,5.18 \pm 2.18,4.20$ \pm 2.14 consecutively, whereas \% of improvement Mean \pm SD at end of treatment, last follow up $=67.89 \pm 11.01,74.97 \pm 9.26$, comparison with baseline there was statistical significance at end of treatment ,last follow up $p$ values $<0.001$. 


\section{Statistical Analysis}

Data were collected, revised, coded and entered to the Statistical Package for Social Science (IBM SPSS) version 23. The qualitative parameters were presented as numbers and percentages while quantitative parameters were presented as mean, standard deviations and ranges. The non-parametric Wilcoxon Rank test was used to compare between GAG score at baseline and at end of treatment and at last follow up. The independent $t$-test was used to assess the relation between demographic data and percentage of improvement at end of study and at last follow up while Spearman correlation coefficients were used to assess the correlation between duration of disease and each of GAG score at different time of measurement and also percentage of improvement at end of treatment and at last follow up (Figures 2-6). The confidence interval was set to $95 \%$ and the margin of error accepted was set to $5 \%$. So, the p-value was considered significant at the level of < 0.05 (Tables 1-4).

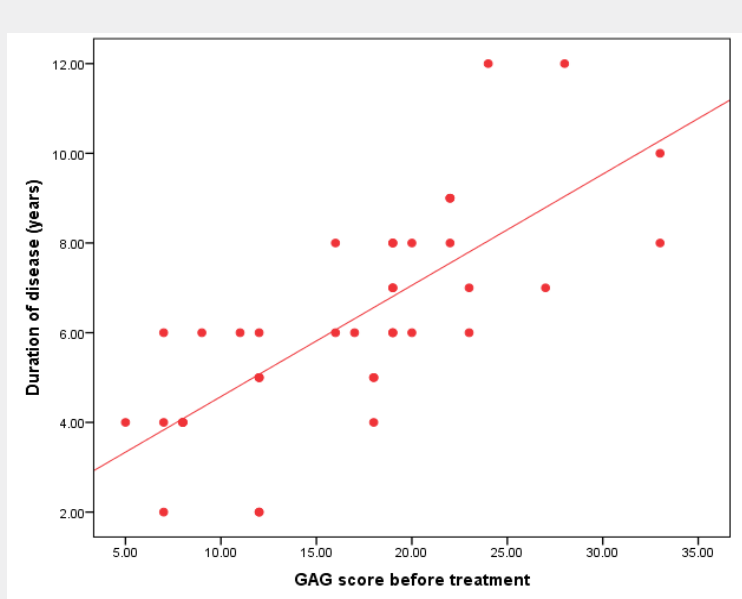

Figure 2: GAG score before, at end of treatment, at last follow up was statistically significant $p$ values $=0.001$, whereas percentage of improvement at end of treatment and at last follow up were not statistically significant $p$ value $=0.378,0.617$, consecutively.

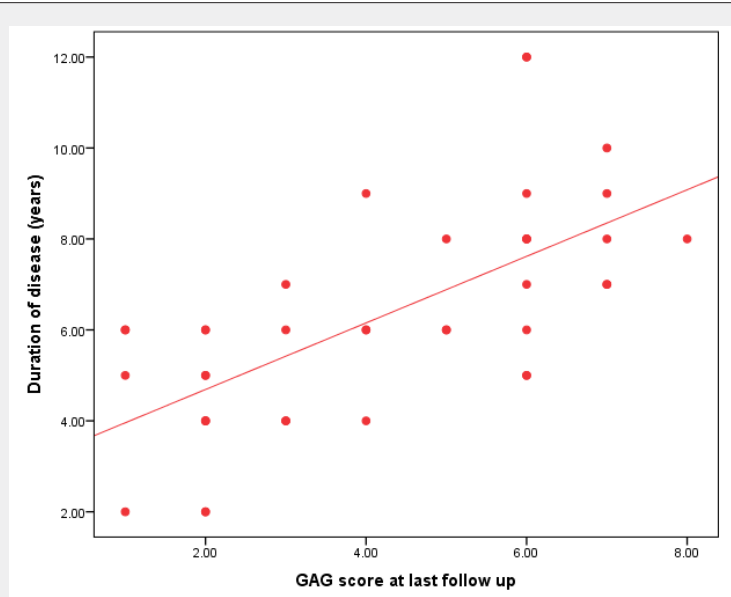

Figure 3: GAG score before, at end of treatment, at last follow up was statistically significant $p$ values $=0.001$, whereas percentage of improvement at end of treatment and at last follow up were not statistically significant $p$ value $=0.378,0.617$, consecutively.

Table 1: Demographic data of the studied cases.

\begin{tabular}{|c|c|c|}
\hline \multicolumn{2}{|c|}{} & No. $\mathbf{4 0}$ \\
\hline \multirow{2}{*}{ Age } & Mean \pm SD & $24.58 \pm 6.41$ \\
\cline { 2 - 3 } & Range & $12-35$ \\
\hline \multirow{2}{*}{ Sex } & Females & $25(62.5 \%)$ \\
\cline { 2 - 3 } & Males & $15(37.5 \%)$ \\
\hline \multirow{2}{*}{ Duration of disease } & Mean \pm SD & $6.30 \pm 2.36$ \\
\cline { 2 - 3 } & Range & $2-12$ \\
\hline
\end{tabular}


Juniper Online Journal of Dermatology \& Cosmetics

\begin{tabular}{|c|c|c|}
\hline \multirow{2}{*}{ Affected area } & Face & $25(62.5 \%)$ \\
\cline { 2 - 3 } & Trunk & $15(37.5 \%)$ \\
\hline \multirow{2}{*}{ Fitzpatrick grading } & 2 & $11(27.5 \%)$ \\
\cline { 2 - 3 } & 3 & $29(72.5 \%)$ \\
\hline \multirow{2}{*}{ Previous medical history } & Negative & $9(22.5 \%)$ \\
\cline { 2 - 3 } & Positive & $31(77.5 \%)$ \\
\hline \multirow{2}{*}{ Topical } & Negative & $8(20.0 \%)$ \\
\hline \multirow{2}{*}{ Systemic } & Positive & $32(80.0 \%)$ \\
\hline
\end{tabular}

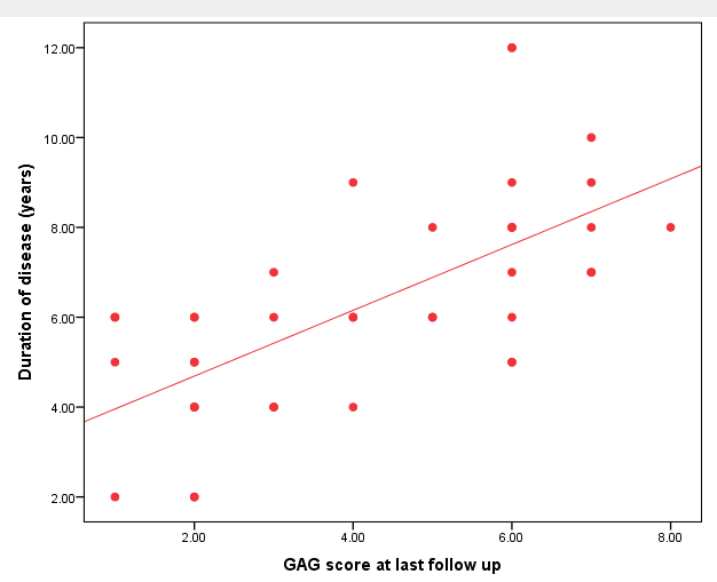

Figure 4 GAG score before, at end of treatment, at last follow up was statistically significant $p$ values $=0.001$, whereas percentage of improvement at end of treatment and at last follow up were not statistically significant $p$ value $=0.378,0.617$, consecutively.

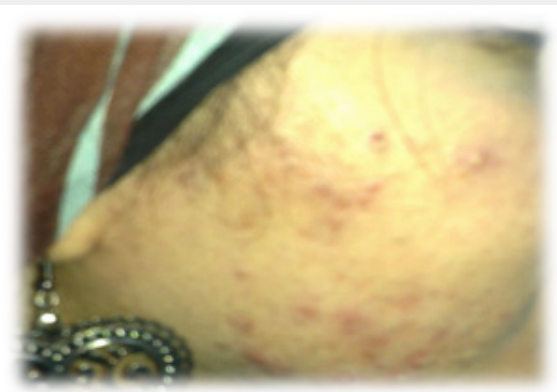

(a)

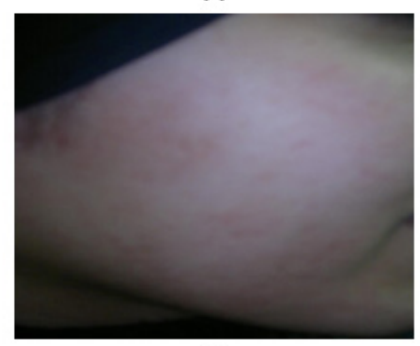

(b)

Figure 5: (a) A case before treatment and (b) A case after treatment. 


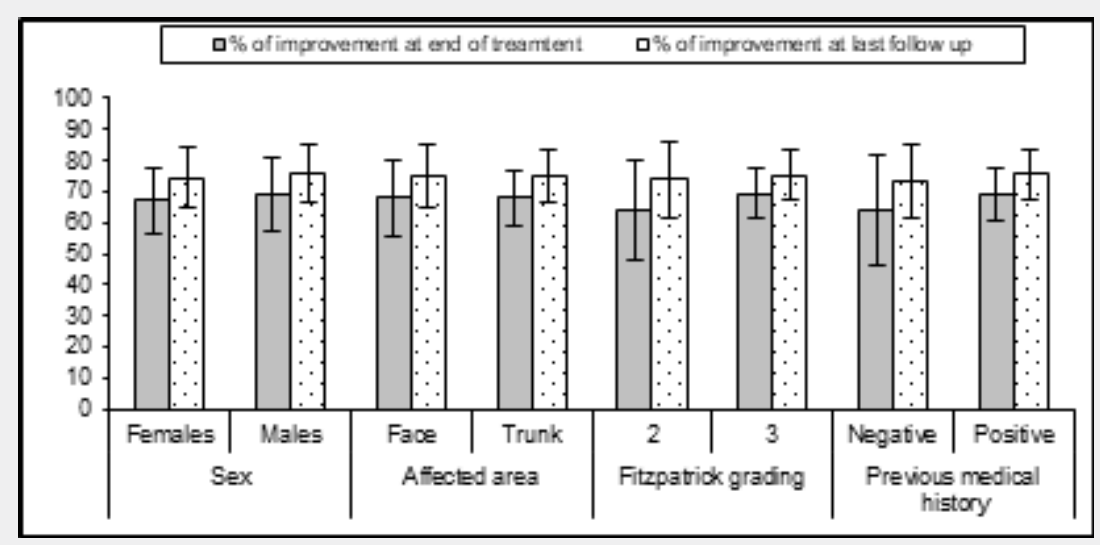

Figure 6: Reveal and display that percentage of improvement at end of treatment and at last follow up with sex, affected area, Fitzpatrick grading and previous medical history was statistically non-significant.

Table 2: Comparison of GAG score at baseline with GAG score at end of treatment and at last follow up with percentage of improvement.

\begin{tabular}{|c|c|c|c|c|}
\hline \multicolumn{2}{|c|}{ No. $=40$} & Baseline & End of treatment & Last follow up \\
\cline { 3 - 5 } & Mean \pm SD & No. $=40$ & No. $=40$ & $4.20 \pm 2.14$ \\
\hline \multirow{2}{*}{ GAG score } & Range & $16.95 \pm 7.05$ & $5.18 \pm 2.18$ & $1-8$ \\
\cline { 2 - 5 }$\%$ of improvement & Mean \pm SD & $5-33$ & $67.89 \pm 11.01$ & $74.97 \pm 9.26$ \\
\cline { 2 - 5 } & Range & -- & $40-91.67$ & $57.14-91.67$ \\
\hline \multirow{2}{*}{ Comparison with baseline } & Test value* & -- & 5.516 & 5.873 \\
\cline { 2 - 5 } & p-value & -- & $<0.001(\mathrm{HS})$ & $<0.001(\mathrm{HS})$ \\
\hline
\end{tabular}

Table 3: Correlation between duration of disease with GAG score at different time of measurement and percentage of improvement at end of treatment and at last follow up.

\begin{tabular}{|c|c|c|}
\hline \multirow{2}{*}{} & \multicolumn{2}{|c|}{ Duration of disease (years) } \\
\cline { 2 - 3 } & $\mathbf{r}$ & $0.001(\mathrm{~S})$ \\
\hline GAG score before & $0.794^{* *}$ & $0.001(\mathrm{~S})$ \\
\hline GAG score at end of treatment & $0.695^{* *}$ & 0.378 (NS) \\
\hline \% of improvement at end of treatment & 0.143 & $0.001(\mathrm{~S})$ \\
\hline GAG score at last follow up & $0.695^{* *}$ & 0.617 (NS) \\
\hline
\end{tabular}

Table 4: Relation between percentage of improvement at end of treatment and at last follow up with sex, affected area, fitzpatrick grading and previous medical history.

\begin{tabular}{|c|c|c|c|c|c|}
\hline \multicolumn{2}{|c|}{ Mean \pm SD } & $\%$ of improvement at & \multirow{2}{*}{$\begin{array}{c}\begin{array}{c}\text { P-value* } \\
\text { Mean } \pm \text { SD }\end{array} \\
0.589(\mathrm{NS})\end{array}$} & \multirow{2}{*}{$\begin{array}{c}\text { \% of improvement at } \\
74.58 \pm 9.47\end{array}$} & \multirow{2}{*}{$\begin{array}{c}\text { P-value* } \\
0.736(\mathrm{NS})\end{array}$} \\
\hline \multirow{2}{*}{ Sex } & Females & $67.15 \pm 10.64$ & & & \\
\hline & Males & $69.13 \pm 11.88$ & & $75.62 \pm 9.19$ & \\
\hline \multirow{2}{*}{ Affected area } & Face & $67.87 \pm 12.19$ & 0.990 (NS) & $75.01 \pm 9.77$ & $0.973(\mathrm{NS})$ \\
\hline & Trunk & $67.92 \pm 9.12$ & & $74.91 \pm 8.67$ & \\
\hline \multirow{2}{*}{ Fitzpatrick grading } & 2 & $64.03 \pm 16.28$ & 0.175 (NS) & $73.88 \pm 12.18$ & $0.651(\mathrm{NS})$ \\
\hline & 3 & $69.36 \pm 8.14$ & & $75.39 \pm 8.11$ & \\
\hline \multirow{2}{*}{$\begin{array}{l}\text { Previous medical } \\
\text { history }\end{array}$} & Negative & $64.12 \pm 17.54$ & 0.248 (NS) & $73.23 \pm 12.18$ & 0.529 (NS) \\
\hline & Positive & $68.99 \pm 8.38$ & & $75.48 \pm 8.41$ & \\
\hline
\end{tabular}




\section{Juniper Online Journal of Dermatology \& Cosmetics}

\section{Discussion}

A prior research study similar to the current research have revealed that aminolaevulinic acid photo dynamic therapy using red light form have an encouraging results for management of moderately severe inflammatory acne vulgaris being considerably more effective and adequate than the doxycycline combination with adapalene gel in decreasing non inflammatory ant total lesions after 6 weeks of starting therapeutic protocol and have a similar impact in the decreasing inflammatory lesions [16-18]. In which there was a statistically significant better decrease in total, inflammatory, and non-inflammatory lesions. after 12 weeks in the combination of PDT research group consequently followed by application of adapalene gel in comparison to the doxycycline and adapalene gel research, those research findings are in partial harmony with the current research study results and could be justified by the fact that photo dynamic therapy mechanism of action at cellular and molecular levels causes damage to sebaceous glands in a selective manner, besides Propionibacterium acnes killing, and an influence on the process of keratinocyte shedding and immunologic system manipulation $[19,20]$.

On the other hand, it was revealed and displayed by various dermatological researchers that, pretreatment with aminolaevulinic acid enhances the effectiveness of red light leading to strong bactericidal impact in vitro. Another interesting issue that was observed by prior research studies that clarify and justify the current research study results and findings that aminolaevulinic acid photo dynamic therapy could trigger sebocytes apoptosis besides down-regulation of their TLR-2 and TLR-4 expressive patterns, that could sustain the of inflamed acne improvement into late stages [21,22]. Another research group of investigators have demonstrated among their obtained research study results a $59 \%$ average reduction of inflammatory lesions with topical 20\% aminolaevulinic acid followed for 12 weeks after one photo dynamic therapy session with red light Various researchers have advised to reduce the total light dosage, photosensitizer strength, and incubation time to avoid adverse side effects such as dyschromia $[1,3,5]$. Interestingly various research groups in prior studies with similar approach and methodology to the current research have shown that Photodynamic therapy using $20 \%$ aminolaevulinic acid or $16 \%$ methyl-aminolaevulinic acid, in conjunction to implementation of artificial light sources in the therapeutic approach e.g. 405 or $630 \mathrm{~nm}$ lamps are effective and promising alternative management options in comparison to doxycline and corticosteroids in acne vulgaris those research findings could be justified by the fact that aminolaevulinic acid being changed to protoporphyrin IX the photosensitizer agent having a broad spectrum for activation (405-640 nm). The absorption spectrum of protoporphyrin IX is extremely triggered at $410 \mathrm{~nm}$ with other peaks around 505-580 and at $635 \mathrm{~nm}$. On the other hand, blue light has a poor penetrative depth within the skin (around $1 \mathrm{~mm}$ ). However, red light ( $635 \mathrm{~nm}$ ) could penetrate in deeper fashion (around $3 \mathrm{~mm}$ ). That justifies the usage of red light in the current research study approach investigated as it was revealed that red-light photodynamic therapy is very efficient in triggering sebaceous glands process of inhibition and destruction $[7,10,15]$.

\section{Conclusion}

Photodynamic therapy mode in conjunction of the photosensitizing agent aminolaevulinic acid 5\% is a promising management mode for moderate to severe forms of acne vulgaris however future research studies are required to be multicentric in fashion with larger sample sizes to verify the research study results with consideration of racial and ethnic differences as a factor that could affect the responsiveness rate of treatment.

\section{References}

1. Williams HC, Dellavalle RP, Garner S (2012) Acne vulgaris. Lancet 379(9813): 361-372.

2. Jeong E, Hong JW, Min JA, et al. (2011) Topical ALA-photodynamic therapy for acne can induce apoptosis of sebocytes and downregulate their TLR-2 and TLR-4 expression. Ann Dermatol 23(1): 23-32.

3. Jeong B, Kim SW, Bae YH (2012) Thermosensitive sol-gel reversible hydrogels. Adv Drug Deliv Rev 64: 154-162.

4. Lucas R, MorenoG, Perez M, Vera A, Aladren S, Milani M (2015) Adherence to drug treatments and adjuvant barrier repair therapies are key factors for clinical improvement in mild to moderate acne: the ACTUO observational prospective multicenter cohort trial in 643 patients. BMC Dermatol 15:17.

5. Kharkwal GB, Sharma SK, Huang YY, Dai T, Hamblin MR (2011) Photodynamic therapy for infections: clinical applications. Lasers Surg Med 43(7): 755-767.

6. Wen X, Li Y, Hamblin MR (2017) Photodynamic therapy in dermatology beyond non-melanoma cancer: An update. Photodiagn Photodyn Ther 19:140-152.

7. Serini SM, Cannizzaro MV, Dattola A, et al. (2019) The efficacy and tolerability of 5-aminolevulinic acid 5\% thermosetting gel photodynamic therapy (PDT) in the treatment of mild-to-moderate acne vulgaris. A two-center, prospective assessor-blinded, proof-ofconcept study. J Cosmet Dermatol 18(1): 156-162.

8. Law MP, Chuh AA, Lee A, Molinari N (2010) Acne prevalence and beyond: acne disability and its predictive factors among Chinese late adolescents in Hong Kong. Clin Exp Dermatol 35(1):16-21.

9. Gollnick HP, Bettoli V, Lambert J, et al. (2016) A consensus-based Practical and daily guide for the treatment of acne patients. J Eur Acad Dermatol Venereol 30(9): 1480-1490.

10. Thiboutot DM, Dréno B, Abanmi A, et al. (2018) Practical management of acne for clinicians: an international consensus from the Global Alliance to Improve Outcomes in Acne. J Am Acad Dermatol 78(2): S1S23.

11. Adler BL, Kornmehl H, Armstrong AW (2017) Antibiotic resistance in acne treatment. JAMA Dermatol 153(8): 810-811.

12. Pariser DM, Eichenfield LF, Bukhalo M, Waterman G, Jarratt M (2016) Photodynamic therapy with methyl aminolaevulinate $80 \mathrm{mg}$ for severe facial acne vulgaris: a randomized vehicle-controlled study. $\mathrm{Br}$ J Dermatol 174(4): 770-777.

13. Sakamoto FH, Lopes JD, Anderson RR (2016) Photodynamic therapy for acne vulgaris: a critical review from basics to clinical practice: part I. Acne vulgaris: when and why consider photodynamic therapy? J Am Acad Dermatol 63(2): 183-193. 
14. Barbaric J, Abbott R, Posadzki P, et al. (2018) Light therapies for acne: abridged Cochrane systematic review including GRADE assessments Br J Dermatol 178(1): 61-75.

15. Yin R, Hao F, Deng J, Yang XC, Yan H (2010) Investigation of optimal ALA concentration applied in topical ALA-PDT for treatment of moderate to severe acne: a pilot study on Chinese people. Br J Dermatol 163(5): 1064-1071.

16. Choi MS, Yun SJ, Beom HJ, Park HR, Lee JB (2011) Comparative study of the bactericidal effects of 5-aminolevulinic acid with blue and red light on Propionibacterium acnes. J Dermatol 38(7): 661-666.

17. Jeong E, Hong JW, Min JA, et al. (2011) Topical ALA-photodynamic Therapy for acne can induce apoptosis of sebocytes and down-regulate their TLR-2 and TLR-4 expression. Ann Dermatol 23(1): 23-32.

18. Walsh TR, Efthimiou J, Dréno B (2016) Systematic review of antibiotic resistance in acne: an increasing topical and oral threat. Lancet Infect Dis 16(3): e23-e33.
19. Megna M, Fabbrocini G, Marasca C, Monfrecola G (2017) Photodynamic therapy and skin appendage disorders: a review. Skin Appendage Disord 2(3-4): 166-176.

20. Wang HW, Lv T, Zhang LL, et al. (2012) Prospective study of topical 5-aminolevulinic acid photodynamic therapy for the treatment of moderate to severe acne vulgaris in Chinese patients. J Cutan Med Surg 16(5): 324-333.

21. Tao SQ Li F, Cao L, et al. (2015) Low-dose topical 5-aminolevulinic Acid photodynamic therapy in the treatment of different severity of acne vulgaris. Cell Biochem Biophys 73(3): 701-706.

22. Boen M, Brownell J, Patel P, Tsoukas MM (2017) The role of photodynamic therapy in acne: an evidence-based review. Am J Clin Dermatol 18(3): 311-321.
This work is licensed under Creative Commons Attribution 4.0 License

DOI: 10.19080/JOJDC.2020.03.555606

\section{Your next submission with Juniper Publishers will reach you the below assets}

- Quality Editorial service

- Swift Peer Review

- Reprints availability

- E-prints Service

- Manuscript Podcast for convenient understanding

- Global attainment for your research

- Manuscript accessibility in different formats

( Pdf, E-pub, Full Text, Audio)

- Unceasing customer service

Track the below URL for one-step submission

https://juniperpublishers.com/online-submission.php 